\title{
Teaching Visually Impaired Learners with Language Disorders: A Reflective Encounter in a Classroom
}

\author{
Daniel L. Mpolomoka*, Masika Monde Sakai \\ Zambian Open University, Zambia.
}

\begin{abstract}
How to cite this paper: Daniel L. Mpolomoka, Masika Monde Sakai. (2021). Teaching Visually Impaired Learners with Language Disorders: A Reflective Encounter in a Classroom. The Educational Review, USA, 5(1), 11-16.

DOI: $10.26855 /$ er.2021.01.003
\end{abstract}

Received: December 10, 2020

Accepted: January 6, 2021

Published: January 22, 2021

Corresponding author: Daniel L. Mpolomoka, Zambian Open University, Zambia.

Email: mpolomokadl@gmail.com

\begin{abstract}
This paper is based on a lived teaching experience at Lions School for the Blind in Ndola, Copperbelt Province in Zambia. The main objective of this study was to explore screening assessments, intervention and teaching strategies employed by the teacher in a classroom of learners with language disorders and have visual impairment. A purely qualitative research employing a case study method. Observations, interviews and document review were the main data collection tools used. The data collected were analysed descriptively and thematically. Findings reveal gaps in screening assessment, intervention and teaching used by the teacher. While these gaps uncover areas to work on and improve practice, the teacher exhibited knowledge and skill in handling learners with language disorders who visual impairments as well. Many of the challenges encountered are structural and require attention of both the school and government authority intervention.
\end{abstract}

Keywords

Visual Impairment, Language Disorder, Assessment, Intervention

\section{Introduction}

The teaching experience shared in this paper was done at Lions School for the Blind in Ndola, a school on Copperbelt, Zambia. The teacher who participated in this study is visually impaired. All the learners with speech, language or communication disorders herein are visually impaired with various severities. So all the learners with speech, language or communication disorders herein are also visually impaired with various severities, but the focus is exclusively on the aspect of speech and language disorders as experienced in the course of teaching them. The learners will bare pseudo names Jafe, Mamu and Monde.

\section{Statement of the Problem}

There are an increasing number of learners in schools who experience language and communication disorders. These may be at early childhood, primary or secondary school level of education. Regardless of the level of education, inability to tackle a learner's language and communication inadequacy can affect their learning and integration into society at large. Advocacy for inclusive schooling clearly translates into enhanced management of teaching-learning strategies and activities for learners. It therefore becomes prudent to probe into the language and communication potentialities of learners through the lens of specialist teachers who handle them. Against this background, this paper is a reflective encounter in a classroom of teaching visually impaired learners with language disorders. 


\section{Objective}

The main objective of this study was to explore screening and or assessments, intervention and teaching strategies employed by specialist teachers in a classroom of learners with visual impairment who have language and communication disorders.

\section{Rationale}

The information in this paper is helpful to teachers, parents and other key stakeholders interested in the education of children with language and communication disorders. It will enrich their classroom practice knowledge and skills of handling learners under discussion in the paper.

In addition, the paper shall help policy makers, young researchers in special education and special education advocates. What is interesting is that it will also build the storehouse of information on special education needs learners with language and communication disabilities.

\section{Case Study 1: Teaching a child with a stuttering disorder}

Below is the verbatim narrative of a teacher's encounter with a child who stutters.

Teaching a grade five class I came across Jafe who had a speech problem, stuttering. At first it was difficult to teach the child until I had to learn from the family by digging into the medical history so as to ascertain the cause of such a challenge. When I got the real cause as having been born like that and that it did not interfere with his cognitive processing of information, I (then) embarked on the strategies that proved to be quiet helpful where teaching and learning were concerned. To begin with, I worked on modalities to motivate the child to participate in discussions through application of discussion method when teaching where the pupils were expected to report what they discussed or read. I was never afraid to ask Jafe to repeat a word or sentence but was patient though I did not supply words or finish thoughts for him. This encouraged him to finish his thoughts and it lead to tremendous improvement of speech expressions.

What we learn from this narrative is the necessities one undertakes in identifying, labelling and eventually placing a child suspected of having a stuttering disorder. This mammoth task heavily lays with the teacher as a contact person with the child in a school. To achieve it, a teacher relies on information from many sources, besides the home and medical reports of the child. The teacher's own knowledge of various disabilities also plays an instrumental role in understanding learners who stutter.

\subsection{Strategies in teaching Jafe}

Below is the verbatim narrative of the teaching strategies employed for the child who stutters.

Having developed a rapport with this learner (Jafe), each time I was addressing the boy directly if need arose I looked for possible facial, hand, or other responses that would signify a speech challenge so that if need be minimal assistance could be given. This used to be so because speech is not the only form of communication so I could deduce meanings by looking at the accompanying gestures as he struggled to pronounce targeted words. I did not urge the boy to slow down or start over again for the completion of thought as this somehow made the stuttering worse. Instead I created a supportive environment free from teasing or mocking. One day when teasing occurred I clarified that such would not be tolerated and punished the offenders. Without showing any signs of favoritism, I appointed Jafe to be the class monitor so that through taking control of the class he would be engaged in speech production practices, thereby improving his speech.

I also privately encouraged him to be attending church and participate in church activities and service (worship) having known that a person with a speech disorder usually can participate in a musical presentation using a musical instrument, even a bell without a problem and this can lead to the erosion of stuttering.

By the end of the term, I noticed that Jafe had regained his self-esteem and had that confidence in himself and showed more concentration on learning than his speech challenges.

The narrative does not really pinpoint any teaching strategy used in teaching the learner, but dwells on periphery ideas that still are worth hinting on. One of them is motivation, which was instrumental in helping the child regain self-confidence and locate himself amongst the peers. This also helped the child's peer appreciate him more as a member of their cohort. The trickledown effect of this is seen in the enhanced interest in earning by the child who stutters. The teaching strategy employed here embraces tenets of cooperative teaching-learning too. 


\subsection{Assessing a child with a stuttering disorder}

The narrative below shows part of the classroom assessment used by a teacher on a child who stutters.

Since in grade five assessment feedback from the pupils is done in form of writing, I deliberately included an oral examination where questions were given in advance for the pupils to go and research and then come and present to the whole class. Apart from that, poems were also encouraged where the best speakers would be rewarded and this encouraged everybody to participate including Jafe. Besides that I developed a checklist within the individualized education program (IEP) in which I recorded strengths and weaknesses from which I was able to build upon my interventions.

With the above information, the teacher saw it fit to formulate intervention goals too, by drawing the Individualized Education Programme (IEP), which was regarded as the first thing in helping children with special needs (Bishop et al., 2016; Bishop et al., 2017; Lewis \& Boorlag, 1988).

\subsection{Intervention}

First and foremost, as a specialist teacher, it is important to realize that an individual needs a loving, supportive network of friends, community, and family. This is in line with what Davis, Shisca, and Howell (2007) and Michael O’Sullivan, Sonia Brownsett, David Copland (2019) also contend. Below are critical areas crucial in teaching-learning intervening in a classroom as shared by a specialist teacher.

So in a classroom situation I encouraged co-operative learning where each learner felt important and developed a sense of belonging which in turn triggered positive self-outlook as witnessed toward the sixth month of the first term. In the course of interventions, I strove to understand what Jafe was saying by focusing on what he wanted rather than how he was saying it. I intentionally spoke clearly and distinctly but naturally being very aware that Jafe was not demoralized or his friends felt that I was giving him special attention. Besides that, I developed an IEP which not only helped him but me to monitor specific speech challenges and improvement.

\section{Case Study 2: Teaching a pupil with communication disorder}

The second encounter we bring to the fore in this paper involved a teacher teaching a child with a communication disorder. This teacher had over 10 years of teaching experience, teaching both learners with and without special education needs. Without doubt, learning takes place through the process of communication and the ability to participate in active and interactive communication with peers and adults in the educational setting is essential for a student to succeed in school (Michael O'Sullivan, Sonia Brownsett, \& David Copland, 2019; Irish Association of Speech and Language Therapists, 2017; Rhea, 2001). Below is the demographic information of the learner and the context within which teaching-learning is being discussed.

The other pupil I taught was Mamu whose communication exhibited a lot of disorders due to a hearing impairment. When teaching this learner I ensured that I was patient and attentive when she was contributing in class so as to give an appropriate response thereby not frustrating her efforts.

In order to serve her better, I engaged in learning sign language which I employed to ensure total communication for effective teaching and learning. Then apart from sitting her in front, I ensured that I spoke naturally, while maintaining an eye contact so that she could also benefit from lip-reading as I talked.

Key questions that emanate from this encounter include: Did the specialist teacher tell us enough about the learner at hand? Did the teacher create a rapport with the learner? What didn't the teacher do for the learner? What else could have been done for the learner? What was done wrongly for and or with the learner? As the paper unfolds, it is anticipated that these questions shall be answered and or made clearer.

\subsection{Assessing a pupil with a communication disorder}

The brief narrative below mirrors part of the classroom assessment modalities the teacher used.

Since Mamu was a bit slow when reading, I gave her more time in order to attempt all the questions in terms of class exercises and/or tests. I also simplified the language for easy understanding and participation.

Simplifying language used with a learner corroborates with what Rhea (2001) contends that classroom teachers who simplify their language give students a much better chance of understanding the intended message, which can foster better teacher-student communication. Notwithstanding this, this teacher should have to read more on assessment and its distinct components so as to narrative in a robust manner how he/she assessing a pupil with a communication disorder. 


\subsection{Intervention}

Intervening in the teaching-learning of a child with a communication disorder is not easy. This is predominantly because learners with disabilities exhibit other disorders that still interfere with their learning besides the observable and diagnosed disorder (Rebecca McCauley, Marc Fey, \& Ronald Gillam, 2017). Below is a narration intervention strategies a teacher we observed employs.

First and foremost, I invited the parents to avail me with the medical history about the learner from which I built my foundation both on understanding her disorder and also to formulate an IEP. One of the intervention strategies I used was task analysis: reducing complex ideas to simple and easy to follow instructions. I promoted sign language by sensitizing other learners to appreciate sign language to be used by everybody in class and also embarked on finding out what the girl's strengths and weaknesses were so that teaching could be done from what she knew to what she did not. In concluding any lessons I made repetitions of key sentences and phrases.

Students with language difficulty have trouble in listening to and interpreting a fast rate of speech. If a teacher pays attention to his/her speech rate and lower it, particularly when communicating a complex concept or theme, it helps learners understand the message being put across (Michael O’Sullivan, Sonia Brownsett, \& David Copland, 2019; Scott, 2009). Some of the learning points here can be deciphered through thought-provoking questions: What can one learn from the intervention employed by the teacher? What gaps do we see in his intervention approach? What else could the teacher have done to meaningfully intervene in the child's learning?

\section{Case Study 3: Teaching a learner with a language disorder}

Below is the verbatim narrative of a teacher's encounter with a learner with a language disorder.

Monde a grade three pupil who had mixed receptive and expressive language disorders which basically involve difficulty understanding and using spoken language. A child may have difficulty understanding what others say, may struggle to put thoughts into words, or both (Toseeb et al., 2017; Martin, 2003). Having understood the challenges of this pupil I skillfully taught an understanding of words and concepts through the use of actual objects and progressed from the concrete to the abstract. Thereafter, I consistently checked for understanding. Deliberately I sat the boy in a position that facilitated the use of prompts, cues or other strategies during teaching and learning.

Before initiating any conversation with Monde, I ensured that the student's attention was first captured and I used slower speech rate where necessary as this facilitated the processing of information. In most cases I used to exaggerate and use gestures when helping this pupil especially when reinforcing understanding or meaning of a word that symbolized an object or an action.

I also employed the use of pictures or photographs to reinforce and review the vocabulary that had been taught. Besides that, I used role play as a regular feature of language learning as this helped alternate speaker's and listener's roles.

The school plays a critical role as an important decision maker and implementer of teaching and support for learning. Effectiveness in teaching regards proficiency in planning and implementing teaching programme in addition to making sound decisions regarding remedial strategies geared towards catering for individual differences among the learners (Abosi, 2007).

\subsection{Assessing a learner with a language disorder}

The following were some of the strategies used by the teacher in assessing a learner with a language disorder.

I gave simple directions in sentences to provide the students with experiences in understanding sentences, for example "Put the book on the table", and had him to repeat what he had heard to check understanding. I also had him to repeat selected words after me to measure masterly of new vocabulary. I used homework, where for example, a passage was given to go and read and then come to explain what they had read and then mention what he could remember as main points. His challenge was mastering and applying the rules of language in English grammar.

\subsection{Intervention}

Three intervening strategies the teacher uses were shared. These were:

$\checkmark \quad$ Modelling the desired behavior: When the child answered a question with a one-word sentence, I used to respond by modeling back with a full, correct sentence, so that the child could hear the words in correct order.

$\checkmark$ Giving choices: Instead of asking the pupil open-ended questions, I asked "either-or questions", so that he/she could choose the correct one.

$\checkmark \quad$ Planning ahead: Knowing that I was to ask or demand some response from Monde, I told him that he would 
be called upon and this gave him more time to compose himself in readiness for reception and expression.

Learning points arising from the intervention strategies shared can be inferred through the following questions: What good practice traits can be deciphered from the intervention narrative above?

\section{Critical Reflection}

The three teachers' encounters with learners with the three types of disabilities (stuttering, communication and language) helped their learners to develop various skills. Such corroborates with what literature advocates for (Sliwinska, et al., 2017; Rebecca et al., 2017; Botting et al., 2016; Conti-Ramsden et al., 2016; Durkin et al., 2016; Godecke et al., 2016) in teaching children with special educational needs (CSENs), especially those with speech disorders. For example, social skills were developed by encouraging learners to communicate with their peers as much as they could. The teachers also encourage learners to sing and play different types of games. They further made reading an interactive experience for learners. For instance, pictures in books and classroom vicinity were discussed and allowed learners to make up new endings or act out the story with puppets. In many instances, where teachers faced challenges, they sought for timely advice from fellow specialists and/or parents. In the end, this made their teaching to become very easy and successful.

\section{Conclusion}

Teaching learners with stuttering, communication and language disorders is not an easy undertaking. This is predominantly because of other associated disabilities that such learners are faced with. The paper has brought to light trends-in-practice of three specialist teachers. There are notable best practices that can be learned from their classroom encounters. At the same time, there are gaps in their teaching and engagement of learners that have been noticed that student teachers and other specialist teachers can be bridged. This paper heavily provided insight into hands-on classroom practices and triangulated with literature on contemporary happenings among specialist teachers handling learners with stuttering, communication and language disorders.

\section{Acknowledgements}

We thank the organising committee of the CBR Conference, 2018. This paper was presented at the 6th CBR Africa Conference, "CBR for resilience building and sustainable development: Leave no one behind" held on 7th-11th May 2018 in Lusaka, Zambia. We would like to sincerely thank the Zambian Open University for the support.

\section{References}

Abosi, O. (2007). Educating children with learning disabilities in Africa learning Disabilities. Research and Practice, $22(3), 196-201$.

Bishop, D. V. M., Snowling, M. J., Thompson, P. A., Greenhalgh, T., \& The CATALISE Consortium. (2016). CATALISE: a multinational and multidisciplinary Delphi consensus study. Identifying language impairmentsin children. PLOS One, 11(7), e0158753. doi:10.1371/journal.pone.0158753

Bishop, D. V. M., Snowling, M. J., Thompson, P. A., Greenhalgh, T., \& The CATALISE Consortium. (2017). Phase 2 of CATALISE: a multinational and multidisciplinary Delphi consensus study of problems with language development: Terminology. Journal of Child Psychology \& Psychiatry. doi:10.1371/journal.pone.0158753

Botting, N., Toseeb, U., Pickles, A., Durkin, K., \& Conti- Ramsden, G. (2016). Depression and anxiety change from adolescence to adulthood in individuals with and without language impairment. PloS One, 11(7).

Conti-Ramsden, G., Durkin, K., Mok, P. L., Toseeb, U., \& Botting, N. (2016). Health, employment and relationships: correlates of personal wellbeing in young adults with and without a history of childhood language impairment. Social Science \& Medicine, $160,20-28$.

Davis, S., Shisca, D., \& Howell, P. (2007). Anxiety in speakers who persist and recover from stuttering. Journal of Communication Disorders, 40, 398-417.

Durkin, K., Toseeb, U., Pickles, A., Botting, N., \& Conti- Ramsden, G. (2016). Learning to drive in young adults with language impairment. Transport research part F: Traffic psychology and behaviour, 42(1), 195-204.

Godecke, E., Armstrong, E. A., Rai, T., et al. (2016). A randomized controlled trial of very Early Rehabilitation in speech after stroke. Int J Stroke, 11: 586-92.

Irish Association of Speech and Language Therapists. (2017). Supporting children with developmental language disorder in Ireland: IASLT Position paper and guidance document 2017. Available at: http://iaslt.ie/attachments/DLD\%20Position\% 20Paper\%20FINAL\%2023MAY2017.pdf. 
Klem, M., Hagtvet, B., Hulme, C., \& Gustafsson, J. E. (2016). Screening for language delay: growth trajectories of language ability in low and high performing children. Journal of Speech, Language and Hearing Research, 59(5), 1035-1035.

Lewis, R. B., \& Boolarg, D. H. (1988). Teaching Special Students in the Main stream (2 ${ }^{\text {nd }}$ ed). Columbus: Merrill Publishing Company.

Martin, D. (2003). Speech and language difficulties in the classroom. Washington: Taylor and Francis.

Michael O'Sullivan, Sonia Brownsett, \& David Copland. (2019). Language and language disorders: Neuroscience to clinical practice.

Pract Neurol, 19: 380-388.

Rebecca J. McCauley, Marc E. Fey, \& Ronald B. Gillam. (2017). Excerpted from Treatment of Language Disorders in Children. (Second Edition). London: Brookes Publishing (www.brookespublishing.com).

Rhea, P. (2001). Language Disorders from Infancy through Adolescence: Assessment and Intervention (2 ${ }^{\text {nd }}$ ed.). St Louis: Mosby.

Sliwinska, M. W., Violante, I. R., Wise, R. J. S., et al. (2017). Stimulating Multiple-Demand cortex enhances vocabulary learning. J Neurosci, 37: 7606-18.

Scott, L. (2009). Helping stutterers. Education Digest, 74(8), 59-62.

Toseeb, U., Pickles, A., Durkin, K., Botting, N., \& Conti-Ramsden, G. (2017). Prosociality from early adolescence to young adulthood: A longitudinal study of individuals with a history of language impairment. Research in Developmental Disabilities, 62, 148-159. 